7. Epstein RM, Street RL Jr. The values and value of patient-centered care. Ann Fam Med. 2011;9(2):100-103.

8. McWhinney IR. Family medicine in perspective. N Engl J Med. 1975; 293:176-181

9. Broekhuizen BDL, Sachs APE, Moons KGM, et al. Diagnostic value of oral prednisolone test for chronic obstructive pulmonary disorders. Ann Fam Med. 2011;9(2):104-109.
11. Van der Wel MC, Buunk IE, van Weel C, Thien TABM, Bakx JC. A novel approach in office blood pressure measurement: 30-minute office blood pressure vs daytime ambulatory blood pressure. Ann Fam Med. 2011;9(2):128-135.

12. Rosser WW, Colwill JM, Kasperski J, Wilson L. Progress of Ontario's Family Health Team model: a patient-centered medical home. Ann Fam Med. 2011;9(2):165-171.

10. Coppin R, Wicke D, Little P. Randomized trial of bulb syringes for earwax-impact on health service utilization. Ann Fam Med. 2011;9(2):110-114.

\title{
EDITORIAL
}

\section{The Values and Value of Patient-Centered Care}

\author{
Ronald M. Epstein, $M D^{1,2}$ \\ Richard L. Street, $J r_{r}, P b D^{3,4}$ \\ 'Departments of Family Medicine, Psychiatry, Oncology, and Nursing, University of Rochester Medical Center, Rochester, New York \\ ${ }^{2}$ Center for Communication and Disparities Research, University of Rochester Medical Center, Rochester, New York \\ ${ }^{3}$ Department of Communication, Texas A\&M University, College Station, Texas \\ ${ }^{4}$ Houston Center for Quality of Care and Utilization Studies, Baylor College of Medicine, Houston, Texas
}

Ann Fam Med 2011;9:100-103. doi:10.1370/afm.1239.

$\mathrm{P}$ atient-centered care has now made it to center stage in discussions of quality. Enshrined by the Institute of Medicine's "quality chasm" report as 1 of 6 key elements of high-quality care, ${ }^{1}$ health care institutions, health planners, congressional representatives, and hospital public relations departments now include the phrase in their lexicons. Insurance payments are increasingly linked to the provision of patient-centered care. Lost in many of the discussions of patient-centered care, however, is the essential and revolutionary meaning of what it means to be patient

Conflicts of interest: authors report none.

\section{CORRESPONDING AUTHOR}

Ronald M. Epstein, MD

Center for Communication and

Disparities Research

University of Rochester Medical Center

1381 South Ave

Rochester, NY 14620

Ronald_Epstein@urmc.rochester.edu centered. The originators of client-centered and patient-centered health care were well aware of the moral implications of their work, which was based on deep respect for patients as unique living beings, and the obligation to care for them on their terms. Thus, patients are known as persons in context of their own social worlds, listened to, informed, respected, and involved in their care-and their wishes are honored (but not mindlessly enacted) during their health care journey. ${ }^{2-6}$ There have been concerns that patientcentered care, with its focus on individual needs, might be at odds with an evidence-based approach, which tends to focus on populations. Fortunately, that debate has been laid to rest ${ }_{i}$ proponents of evidence-based medicine now accept that a good outcome must be defined in terms of what is meaningful and valuable to the individual patient. ${ }^{7}$ Patient-centered care, as does evidence-based medicine, considers both the art of generalizations and the science of particulars. ${ }^{8}$

Patient-centered care is a quality of personal, professional, and organizational relationships. Thus, efforts to promote patient-centered care should 
consider patient-centeredness of patients (and their families), clinicians, and health systems. ${ }^{9,10}$ Helping patients to be more active in consultations changes centuries of physician-dominated dialogues to those that engage patients as active participants. Training physicians to be more mindful, informative, and empathic transforms their role from one characterized by authority to one that has the goals of partnership, solidarity, empathy, and collaboration. Systems changes that unburden primary care physicians from the drudgery of productivity-driven assembly-line medicine can diminish the cognitive overload and exhaustion that makes medical care anything but caring or patient-centered.

Confusion about what patient-centered care really means, however, can produce efforts that are superficial and unconvincing. In the name of patientcenteredness, hospitals have been adopting models used by boutique hotels with greeters, greenery, and gadgetry. Although such amenities might enhance the patient's experience, they do not necessarily achieve the goals of patient-centered care. Calls for patientcentered care have often emphasized the implementation of infrastructural changes. ${ }^{10}$ These changes, such as electronic health records and advanced access scheduling, may be necessary to move medical care into the 21st century, but they should not be conflated with achieving patient-centered care. Simply implementing an electronic health record in itself is not patient-centered unless it strengthens the patientclinician relationship, promotes communication about things that matter, helps patients know more about their health, and facilitates their involvement in their own care. Similarly, advanced access scheduling could as likely lead to greater access to an overworked uncaring functionary as it could to a familiar and caring presence in time of need.

With social changes in medicine, the operational definition of patient-centered care is changing, and measures should reflect those changes. ${ }^{11}$ Early measures of patient involvement in care, for example, asked patients whether they had opportunities to ask questions. A patient who is accustomed to a passive role in care might be satisfied by the physician's rushed, "Any questions?" at the end of a visit and habitually answer no; this patient may never have experienced a more active invitation for involvement. A patient-centered approach should do more. The physician should invite the patient to participate: "I want to make sure that I've helped you understand everything you need to understand about your illness. Patients usually have questions because it can be complicated. Could you tell me what you understand, and then I can help clarify...?" Similarly, information should be tailored to patients' needs to permit meaningful deliberation and shared mind. ${ }^{12}$

Because investments in improving patient-centered care are being undertaken on a large scale, developing adequate measures has taken on some urgency. How can we know whether interventions intended to improve patient-centered care have achieved their goals? How can we meaningfully reward practitioners and health systems that achieve patient-centered care? In their article in this issue of the Annals, Hudon et $\mathrm{al}^{13}$ provide an important service to clinicians and researchers of patient-centered care. The appendices provide a valuable resource of various related measures, ones that can be used for research and assessment purposes. Perhaps more importantly, the article identifies several shortcomings of current approaches to measuring patient-centered care, many of which result from confusion between its associated philosophy, behaviors, and outcomes.

First, philosophically, patient-centered care is an approach to care and perceived as the right thing to do. Taking this view, behaviors associated with patientcentered care, such as respecting patients' preferences, should be justified on moral grounds alone, independent of their relationship to health outcomes.

Second, many of the measures confound behaviors with outcomes, leading to confusing results. Consider a situation in which a patient is satisfied with her physician's listening skills, yet her chronic disease control worsens. ${ }^{14}$ Has patient-centered care been accomplished? Researchers are only beginning to model pathways through which patient-centered care behaviors contribute to better outcomes. ${ }^{15}$ The proximal outcomes - the patient feeling known, respected, involved, engaged, and knowledgeable-are desirable in and of themselves and may mitigate a patient's distress associated with illness and uncertainty. ${ }^{16}$ The effect of communication on health outcomes, however, most often will be indirect. Thus, it is important to understand which proximal outcomes of patientcentered care-feeling understood, trust, or motivation for change-might contribute most strongly to improved adherence and self-care.

Third, it is commonly assumed that the patient is the best judge of whether an interaction is patient centered. This assumption is understandable, yet sometimes what patients think they want (eg, a drug) is not what they need (eg, information). A doctor who acquiesces to a patient's request for unnecessary antibiotics may have a happy patient, yet inappropriate prescribing could hardly be called patient-centered care. Several other concerns about patient's reports should be considered. Many measures, such as those highlighted by Hudon et al, confound asking patients to report 
on things that actually happened (eg, "We discussed and agreed....") with their own subjective assessments of those behaviors (eg, "My doctor understood me today."). Survey measures should take into account that patients often overrate the degree to which they have been informed about and understand their illnesses. ${ }^{17}$ The disconnect between high patient satisfaction with care and poor understanding and participation in care is greatest for those with low literacy, poor English fluency, cognitive impairment, and social disadvantage..$^{17,18}$ Thus, patients might need to be trained to assess physicians' patient-centeredness; but, that training itself will likely induce patient-centered behaviors.

Finally, patients' and physicians' perceptions of a clinical encounter differ, ${ }_{1}^{19}$ and each differs somewhat from the assessments of communication experts using sophisticated coding of audio-recorded clinical encounters. ${ }^{20,21}$ For example, patients may state that they participated in decision making, yet observations of the interaction find little evidence of patient involvement. ${ }^{22}$ One approach to this conundrum is to use standardized patients inserted covertly into physicians' practices (with their permission) to provide nuanced assessments of physicians' patient-centered behaviors and to control for variability in patient presentation. ${ }^{23}$

Patient-centered care is prominently positioned on the political agenda, but our measures are not yet up to the challenge of ensuring that it is happening. Fortunately, several groups with sufficient expertise and infrastructure are developing new measures, building on the laudable efforts of their predecessors. New measures should undergo cognitive testing and piloting in a variety of settings, recognizing that no single measure will adequately capture relevant aspects of patient-centered care across clinical contexts and populations. For comparing overall quality of interpersonal care across health care settings, a brief general measure, such as the Consumer Assessment of Health Plans Survey (CAHPS), should be mentioned. ${ }^{24}$ CAHPS is widely adopted in the United States; 3 of the items correspond to domains of patient-centered care. Although some settings use CAHPS and similar tools to identify individual practitioners in need of remediation, these tools were not designed for that purpose. To provide actionable feedback to individual clinicians or health systems about what needs to be changed to achieve patient-centered care, more detailed surveys, standardized patient assessments, or direct observation will be necessary. Most importantly, relevant stakeholders-patients, their families, clinicians, and health systems-should be involved in developing a family of measures to capture important

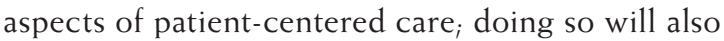
provide an opportunity to align stakeholders' perspec- tives on what counts as patient-centered care and how it should be accomplished.

To read or post commentaries in response to this article, see it online at http://www.annfammed.org/cgi/content/full/9/2/100.

Key words: Patient-centered care; provider-patient relations; standardized patients; communication; measurement

Submitted January 23, 2011; accepted January 27, 2011.

\section{References}

1. Committee on Quality of Health Care in America. Institute of Medicine. Crossing the Quality Chasm : A New Health System for the 21st Century. Washington, DC: National Academy Press; 2001.

2. Rogers CR. The characteristics of a helping relationship. In: Rogers CR, ed. On Becoming a Person: A Therapist's View of Psychotherapy. Boston, MA: Houghton Mifflin; 1961;39-58.

3. MCWhinney IR. Patient-centred and doctor-centred models of clinical decision making. In: Sheldon M, Brook J, Rector A, eds. Decision Making in General Practice. London: Stockton; 1985;31-46.

4. Gerteis M, Edgeman-Levitan S, Daley J, Delbanco T. Through the Patient's Eyes: Understanding and Promoting Patient-Centered Care. 1st ed. San Francisco, CA: Jossey-Bass, 1993.

5. Balint M. The Doctor, His Patient, and the Illness. New York, NY: International Universities Press; 1957.

6. Entralgo PL. Doctor and Patient. New York, NY: McGraw-Hill Book Company; 1969.

7. Guyatt G, Montori V, Devereaux PJ, Schünemann H, Bhandari M. Patients at the center: in our practice, and in our use of language. ACP J Club. 2004;140(1):A11-A12.

8. McWhinney IR. 'An acquaintance with particulars...'. Fam Med. 1989;21(4):296-298.

9. Epstein RM, Street RL Jr. Patient-Centered Communication in Cancer Care: Promoting Healing and Reducing Suffering. Bethesda, MD: National Cancer Institute, NIH; 2007.

10. Epstein RM, Fiscella K, Lesser CS, Stange KC. Why the nation needs a policy push on patient-centered health care. Health Aff (Millwood). 2010;29(8):1489-1495.

11. Epstein RM, Franks P, Fiscella K, et al. Measuring patient-centered communication in patient-physician consultations: theoretical and practical issues. Soc Sci Med. 2005;61(7):1516-1528.

12. Epstein RM, Peters E. Beyond information: exploring patients' preferences. JAMA. 2009;302(2):195-197.

13. Hudon C, Fortin M, Haggerty JL, Lambert M, Poitras M-E. Measuring patient perceptions of patient-centered care: a systematic review of tools for family medicine. Ann Fam Med. 2011;9(2):155-164.

14. Kinmonth AL, Woodcock A, Griffin S, Spiegal N, Campbell MJ: The Diabetes Care From Diagnosis Research Team. Randomised controlled trial of patient centred care of diabetes in general practice: impact on current wellbeing and future disease risk. BMJ. 1998;317(7167):1202-1208.

15. Street RL Jr, Makoul G, Arora NK, Epstein RM. How does communication heal? Pathways linking clinician-patient communication to health outcomes. Patient Educ Couns. 2009;74(3):295-301.

16. Arora NK, Weaver KE, Clayman ML, Oakley-Girvan I, Potosky AL. Physicians' decision-making style and psychosocial outcomes among cancer survivors. Patient Educ Couns. 2009;77(3):404-412.

17. Peters E, Hibbard J, Slovic P, Dieckmann N. Numeracy skill and the communication, comprehension, and use of risk-benefit information. Health Aff (Millwood). 2007;26(3):741-748. 
18. Fiscella K, Epstein RM. So much to do, so little time: care for the socially disadvantaged and the 15-minute visit. Arch Intern Med. 2008;168(17):1843-1852.

19. Street RL Jr, Haidet P. How well do doctors know their patients? Factors affecting physician understanding of patients' health beliefs. J Gen Intern Med. 2011;26(1):21-27.

20. Stewart M, Brown JB, Donner A, et al. The impact of patient-centered care on outcomes. J Fam Pract. 2000;49(9):796-804.

21. Epstein RM, Franks P, Shields CG, et al. Patient-centered communication and diagnostic testing. Ann Fam Med. 2005;3(5):415-421.
22. Saba GW, Wong ST, Schillinger D, et al. Shared decision making and the experience of partnership in primary care. Ann Fam Med. 2006;4(1):54-62.

23. Srinivasan M, Franks P, Meredith LS, Fiscella K, Epstein RM, Kravitz RL. Connoisseurs of care? Unannounced standardized patients' ratings of physicians. Med Care. 2006;44(12):1092-1098.

24. Solomon LS, Hays RD, Zaslavsky AM, Ding L, Cleary PD. Psychometric properties of a group-level Consumer Assessment of Health Plans Study (CAHPS) instrument. Med Care. 2005;43(1):53-60.

\section{CHANGE-OF-ADDRESS FORM FAMILY MEDICINE}

Please complete this form and mail to the following address or fax to Annals Circulation at 913-906-6080:

Annals of Family Medicine, Circulation Department, 11400 Tomahawk Creek Pkwy, Leawood, KS 66211-2680

Check if member of sponsoring organization: $\square$ AAFP $\square$ ABFM $\square$ STFM $\square$ ADFM

$$
\square \text { AFMRD } \square \text { NAPCRG } \square \text { CFPC }
$$

ID number from label on your journal cover

OLD Information (Please print.)

$$
\text { Name }
$$

Company (if applicable)

Address (Street plus Apt or Ste)

City

Country

Telephone

E-Mail
NEW Information (Please print.)

\begin{tabular}{ll}
\hline Name \\
\hline Company (if applicable) & \\
\hline Address (Street plus Apt or Ste) & \\
\hline City & Postal Code (9-digit ZIP for US) \\
\hline Country & \\
\hline Telephone & \\
\hline E-Mail &
\end{tabular}

